\title{
ELECTROPHORETIC DIFFERENTIATION OF THE FIBRE TYPES OF ADDUCTOR MANDIBULAE, STERNOHYOIDEUS AND PROTRACTOR HYOIDEUS MUSCLES OF THE CARP (CYPRINUS CARPIO L.)
}

\author{
B. Focant, F. HuriauX and P. Vandewalle* \\ Université de Liège, Laboratoire de Biocheimie Musculaire, Institute de Chimie B6, Sart Tilman, B-4000 Liège, \\ Belgique (Tel: 041 561361) and \\ *Université de Liège, Laboratoire de Morphologie Fonctionnelle, Institute de Zoologie, quai Van Beneden, 22, \\ B-4020 Liège, Belgique
}

(Received 1 March 1983)

\begin{abstract}
The estimation of relative proportions of white and red myosin light chains separated on PAGE allows the calculation of red fibre content of several carp head muscles.

2. The muscle composition appears related to the function: muscle acting during slow respiratory movements possesses a higher amount of red fibres $\left(A_{1} \beta\right.$ and $\left.A_{3}\right)$. Moreover, most of the examined muscles are heterogeneous with a set of white fibres adjacent to red ones.

3. Peculiar fibres observed in protractor hyoideus lateral: they show a white type myosin and contain a low amount of myoglobin while the parvalbumins and lactic dehydrogenase isoenzymes distributions are typical of the red type.
\end{abstract}

\section{INTRODUCTION}

Fish muscles are composed of three main types of skeletal fibres: red (slow), pink (intermediate) and white (fast) fibres which are successively recruited when the speed of swimming increases (Johnston et al., 1977). In the trunk musculature, fibre types are well localised in homogeneous regions: pure white and red muscles exist respectively in dorsal body musculature and at the level of the lateral line; pink fibres are situated between the two other types. They can be distinguished by their colour, their metabolic pattern and their myofibrillar proteins (Syrovy et al., 1970; Hamoir et al., 1972; Huriaux and Focant, 1974; Focant et al., 1976; Focant and Huriaux, 1976; Johnston et al., 1977). Fish white and red myosins show the same main differences in light chain composition as mammals do but with a greater variability in electric charge and molecular weight. Pink fibres exhibit the myosin type of white muscle but have a more oxidative metabolism. Characteristic light chain patterns of the white and red fibre myosins were previously used in order to differentiate several trunk and fin muscles of the carp (Huriaux and Focant, 1974). A heterogeneous fibre composition was usually observed. The more or less marked "red" appearance of a muscle agreed with its peculiar sarcoplasmic composition (Hamoir et al., 1972).

Fish head muscles fulfill a variety of functional behaviours (Ballintijn, 1969a; Akster and Osse, 1978; Vandewalle, 1979). In the carp, electromyographic studies of Ballintijn (1969b) and Ballintijn et al. (1972) correlated jaw and opercular muscles with the movements involved in respiration, coughing and feeding.

Hamoir et al. (1981) compared the sarcoplasmic extracts of 16 carp head muscles from the points of view of myoglobin and hemoglobin contents, parvalbumin content and pattern as well as the lactate dehydrogenase isozymic distribution. Their results suggest the existence of more than three fibre types and agree well with the earlier physiological study.

To fill the lack of biochemical data on the molecular differentiation of the contractile proteins from carp head muscles, we have examined in the present work the myosins of four jaw adductor muscles and two other peculiar head muscles of this fish. The subunit composition of myosins has been analysed using one- or two-dimensional PAGE, in comparison with homogeneous white and red body muscles. Proportions of light chains of white and red myosins have allowed us to establish the fast or slow type of every muscle and to compare this characteristic with electromyographic measurements carried out at the same time by Vandewalle et al. (1983). Preliminary biochemical results have already been published (Focant et al., 1982).

\section{MATERIALS AND METHODS}

Mirror carp (Cyprinus carpio L.) weighing from 1 to $6 \mathrm{~kg}$ were purchased from a local fish dealer and kept in a pond. They were anaesthetized in a $0.01 \%$ solution of tricaine methane-sulfonate (MS 222, Sandoz Ltd) for $1 \mathrm{hr}$ and killed by decapitation.

The jaw adductor muscles were carefully dissected: whole adductor mandibulae $A_{1} \alpha, A_{1} \beta, A_{2}$ and $A_{3}$ were successively removed (Fig. 1). In addition, the heterogeneous looking muscles were divided according to their colour: 2 parts were selected in add.mand. $A_{1} \alpha\left(A_{1} \alpha I\right.$ and $\left.A_{1} \alpha I I\right), 3$ parts in add.mand. $A_{1} \beta\left(A_{1} \beta I, A_{1} \beta I I\right.$ and $\left.A_{1} \beta I I I\right)$ and 2 parts in add.mand. $A_{3}\left(A_{3} I\right.$ and $\left.A_{3} I I\right)$.Only $A_{2}$ appears homogeneously pale; $A_{1} \alpha$ II, $A_{1} \beta$ II and $A_{3}$ II look very red 

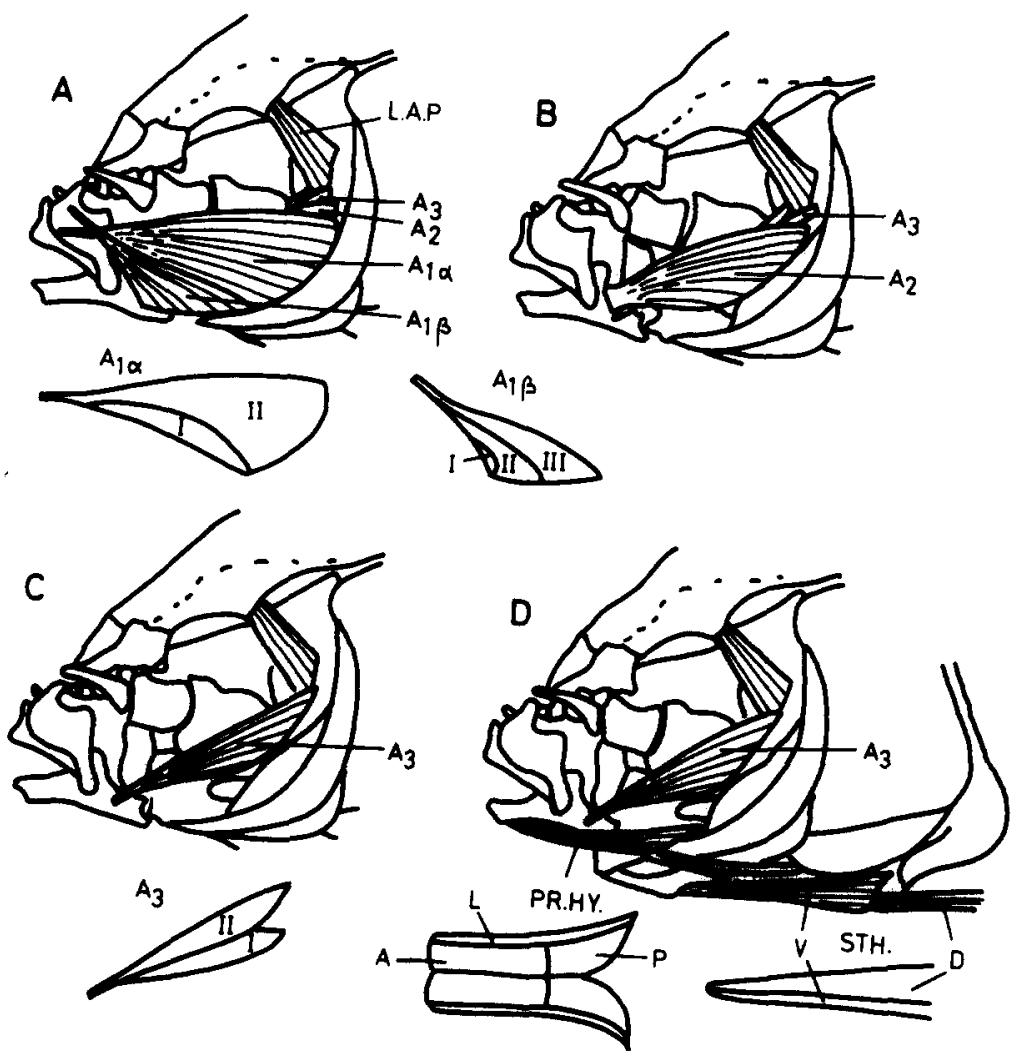

Fig. 1. Lateral view of the carp head showing the muscles dissected and their different parts. (A) Adductor mandibulae $\left(A_{1} \alpha(I, I I)\right.$ and $A_{1} \beta(I, I I, I I) ;(B)$ adductor mandibulae $A_{2} ;(C)$ adductor mandibulae $A_{3}(I$, II); (D) protractor hyoideus (L, lateral, A, anterior, P, posterior) and sternohyoideus (V, ventral, D, dorsal). L.A.P., levator arcus palatini.

whereas $A_{1} \alpha I, A_{1} \beta I, A_{1} \beta I I I$ and $A_{3} I$ are pink coloured. The relative importance of the selected parts of muscles is given in Table 1 .

The sternohyoideus was separated into a ventral part (STH.V) and a dorsal one (STH.D). Three parts were isolated from the protractor hyoideus: an anterior (PR.HY.A), a lateral (PR.HY.L.) and a posterior part (PR.HY.P) (Hamoir et al., 1981) (Fig. 1 and Table 1).

Samples of white trunk muscle and red lateral line muscle were chosen as references. Special care was taken to remove pink fibres from the lateral line red muscle strip. Fast (tibialis anterior) and slow (soleus) rabbit muscles were also used as references of typical mammalian myosins.

Immediately after the dissection, the samples were weighed, kept in a Tris-glycerol solution $(0.01 \mathrm{M}$ Tris- $\mathrm{HCl}$, $0.05 \mathrm{M} \mathrm{KCl}, 50 \%$ glycerol $(\mathrm{v} / \mathrm{v}) ; \quad 0.002 \mathrm{M}$ 2-mercaptoethanol; $\mathrm{pH} 7.5$ ) at $-20^{\circ} \mathrm{C}$ or used without delay for the isolation of the actomyosin.

\section{Preparation of actomyosin}

This was made according to Focant $e t$ al. $(1981)$ at $4^{\circ} \mathrm{C}$ in the presence of $0.002 \mathrm{M}$ 2-mercaptoethanol. The final washing was omitted when the amount of muscle was too small.

\section{Sample incubation}

Actomyosin samples were incubated in $0.0625 \mathrm{M}$ Tris- $\mathrm{HCl}, 0.69 \mathrm{M} \mathrm{SDS}, 2 \%$ sucrose, $4 \%$ 2-mercaptoethanol, pH 7.5 and heated for $3 \mathrm{~min}$ at $100^{\circ} \mathrm{C}$. All samples at the concentration of approximately $5 \mathrm{mg} / \mathrm{ml}$ were stored at $-20^{\circ} \mathrm{C}$ until use.

\section{Polyacrylamide gel electrophoresis}

One-dimensional discontinuous polyacrylamide gel electrophoreses in the presence of $0.1 \%$ SDS were performed in a vertical slab of $18 \times 8 \times 0.2 \mathrm{~cm}$ using a main gel of $15 \%$ acrylamide; $0.375 \mathrm{M}$ Tris-HCl; pH 8.8 buffer (Laemmli, 1970). Two-dimensional polyacrylamide gel electrophoreses were made according to O'Farrell (1975) using 6.25\% Pharmacia Ampholytes of $\mathrm{pH}$ range 4-6.5 for isoelectric focusing gels and second dimension slab gels of $15 \%$ acrylamide and $0.087 \%$ bisacrylamide. Conditions for staining and destaining have previously been described (Huriaux and Focant, 1977).

\section{Estimation of the amount of red myosin}

Densitometry of SDS polyacrylamide gels was performed with the Helena Quick-Scan apparatus (Baumont, Texas).

Table 1. Relative proportions (in \% of weight) of selected parts of head muscles

\begin{tabular}{|c|c|c|c|c|c|c|c|c|c|c|c|}
\hline \multicolumn{2}{|c|}{$A_{1} \alpha$} & \multicolumn{3}{|c|}{$\mathbf{A}_{1} \beta$} & \multicolumn{2}{|c|}{$\overline{A_{3}}$} & \multicolumn{2}{|c|}{ STH } & \multicolumn{3}{|c|}{ PR.HY. } \\
\hline I & II & I & II & III & I & II & $\mathrm{V}$ & D & L & A & $\mathrm{P}$ \\
\hline 80 & 20 & $\ll 1$ & 60 & 40 & 35 & 65 & 30 & 70 & 15 & 50 & 35 \\
\hline
\end{tabular}


To evaluate the amount of red muscle, we made use of two formulas of computation based on the relative amount of light chains $\mathrm{LC}_{1} \mathrm{R}$ vs $\mathrm{LC}_{1} \mathrm{~W}+\mathrm{LC}_{3} \mathrm{~W}$ or $\mathrm{LC}_{1} \mathrm{R}$ vs $\mathrm{LC}_{3} \mathrm{~W}$. These formulas take into account the stoichiometry of myosin light chains: $2 \mathrm{~mol}$ of $\mathrm{LC}_{1} \mathbf{R}$ and $2 \mathrm{~mol}$ of $\left(\mathrm{LC}_{1} \mathrm{~W}+\mathrm{LC}_{3} \mathrm{~W}\right)$ or $1.3 \mathrm{~mol}$ of $\mathrm{LC}_{3} \mathrm{~W}$ per $\mathrm{mol}$ of myosin (Huriaux and Focant, 1977). Moreover, the amount of each light chain was corrected for its apparent molecular weight in order to take into account the differences in stain affinity of the electrophoretic bands.

The percentage of red myosin was thus determined as follows:

$$
\frac{\frac{\mathrm{LC}_{1} \mathrm{R}}{24,700}}{\frac{\mathrm{LC} \mathrm{C}_{1} \mathrm{R}}{24,700}+\left(\frac{\mathrm{LC} \mathrm{C}_{1} \mathrm{~W}}{25,000}+\frac{\mathrm{LC}_{3} \mathrm{~W}}{16,400}\right)} \times 100
$$

or

$$
\frac{\frac{\mathrm{LC}_{1} \mathrm{R}}{24,700}}{\frac{\mathrm{LC}_{1} \mathrm{R}}{24,700}+\left(\frac{2}{1.3} \cdot \frac{\mathrm{LC}_{3} \mathrm{~W}}{16,400}\right)} \times 100 .
$$

\section{RESULTS}

\section{Body muscles}

The one-dimensional electrophoretic patterns of myofibrillar proteins from some carp white and red muscles have partially been described (Focant et al., 1974; Focant and Huriaux, 1976; Huriaux and Focant, 1974, 1977). These results show that discon- tinuous polyacrylamide gel electrophoresis in the presence of SDS which allows the determination of the molecular weight reveals the presence of 3 light chains in white muscle myosin ( $\mathrm{LC}_{1} \mathrm{~W} 25,000 ; \mathrm{LC}_{2} \mathrm{~W}$ 17,500 and $\mathrm{LC}_{3} \mathrm{~W} 19,000-20,000$ daltons) (Fig. 2A). The abnormally high molecular weight of carp $\mathrm{LC}_{3} \mathrm{~W}$ results from an aberration of mobility at alkaline $\mathrm{pH}$ and an accurate value of 16,400 daltons can be obtained with a neutral continuous buffer system (Huriaux and Focant, 1978). Red muscle myosin is characterized by two light chains: a $L_{1} R$ of 24,700 daltons and $a \mathrm{LC}_{2} \mathrm{R}$ of 17,400 daltons (Fig. $2 \mathrm{C}$ ).

Actomyosins from carp white and red muscles were also analysed on two-dimensional polyacrylamide gel electrophoresis. This method displays a better separation of proteins according to both the molecular weight and the isoelectric point. They were compared with the actomyosins of rabbit corresponding muscles used as reference. Electrophoretic patterns of mixture of carp and rabbit actomyosins are illustrated in Fig. 3(A) and (C). Carp and rabbit light chain appear all distinct, allowing easy muscle identification. Only one form of $\mathrm{LC}_{1} \mathrm{R}$ occurs in the case of carp red muscle myosin while two forms $L_{1} R$ and $L_{1} R^{\prime}$ with very distinct isoelectric points are present in rabbit red muscle.

\section{Head muscles}

In a first step, the actomyosins of add.mand. $A_{1} \alpha$, $A_{1} \beta, A_{2}$ and $A_{3}$ of three carps (right and left muscles of carps weighing respectively $1.2,2.9$ and $6.0 \mathrm{~kg}$ )

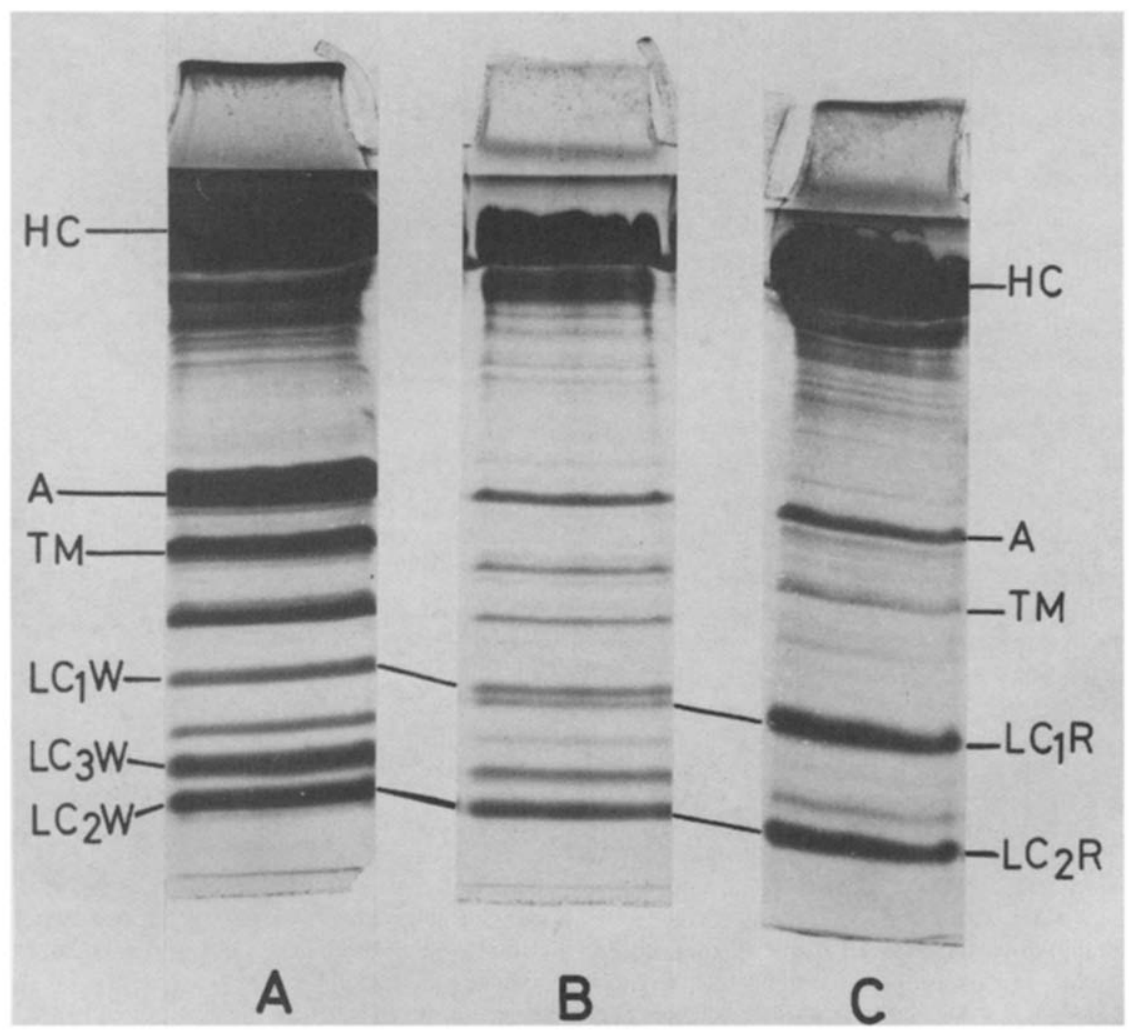

Fig. 2. Discontinuous polyacrylamide gel electrophoresis (15\% acrylamide) in the presence of SDS of carp actomyosin. (A) Dorsal white muscle; (B) adductor mandibulae $A_{3}$; (C) lateral line red muscle (W, white; $\mathbf{R}$, red). 


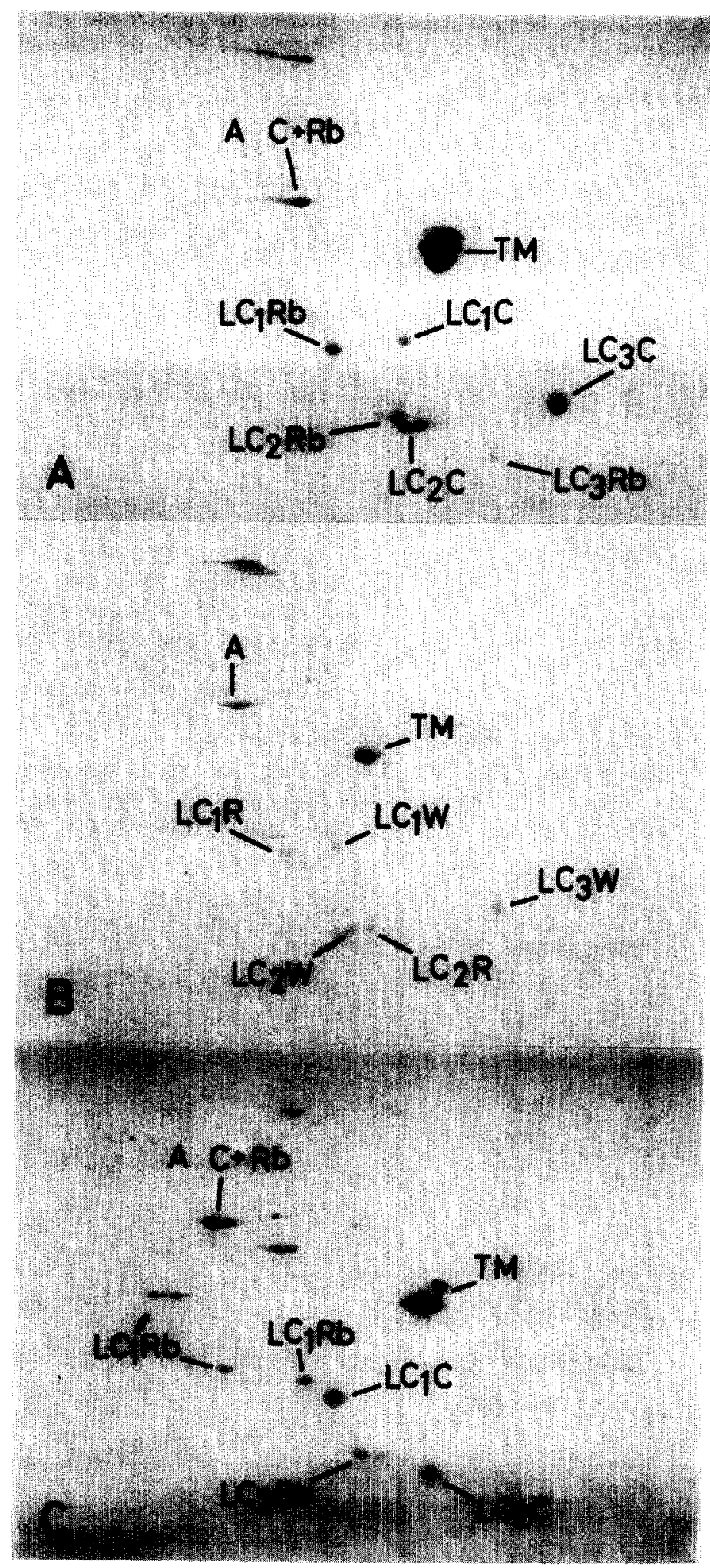

Fig. 3. Two-dimensional polyacrylamide gel electrophoresis of actomyosins of: (A) rabbit fast-twitch and carp dorsal white muscles; (B) adductor mandibulae $A_{3}$ muscle; (C) rabbit slow-tonic and carp lateral line red muscles. Horizontal (first dimension): isoelectric focusing in the $\mathrm{pH}$ range 6.5 (left) -4.0 (right). Vertical (second dimension): separation according to molecular weight in the presence of SDS (C, carp; $\mathrm{Rb}$, rabbit; W, white; $\mathrm{R}$, red). 
were compared with actomyosins of white and red reference trunk muscles, on SDS one-dimensional gels.

Muscles like add.mand. $A_{1} \beta$ and chiefly $A_{3}$ (Fig. 2B) were characterized by the simultaneous presence of white and red myosin light chains. As $L C_{1} W$ and $L_{C} \mathbf{W}$ as well as $L_{C} R$ are well separated on the electrophoretograms, the percentages of the red fibres in muscles were determined (Fig. 4A). Add.mand. $A_{1} \beta$ and mainly $A_{3}$ exhibit a significant amount of red type myosin (respectively 15 and $30 \%$ ). Muscles isolated from biggest carps appear to contain more red fibres. Jaw adductor muscles can thus be ordered on the basis of electrophoretic data, according to their red fibre content: $\mathbf{A}_{2}<\mathbf{A}_{1} \alpha<\mathbf{A}_{3} \beta<\mathbf{A}_{3}$.

Two-dimensional electrophoresis of the different adductor muscles gives a good separation of each light chain. These results confirm the observations based on one-dimensional gel electrophoreses but with a better resolution of all myosin subunits, although not allowing their quantitative evaluation. Add.mand. $A_{2}$ shows only the three light chains of fast myosin whereas in $A_{3}$ (Fig. 3B) five light chains are visible, the two red light chains being in higher concentration then in $A_{1} \beta$.

The muscle distribution proceeding from the amount of red myosin agrees well with the observations of Ballintijn (1969b) and Ballintijn et al. (1972) on physiological activities of carp jaw muscles during respiration and feeding: increase in red myosin content corresponds to longer contraction time.

Nevertheless, some adductor muscles, when they are closely examined, appear constituted of several fibres bundles areas differing by their red coloration. Consequently, we have also compared parts of head muscles isolated according to their relatively homogeneous white or red colour. The same parts were subjected in parallel to electromyographic measure-
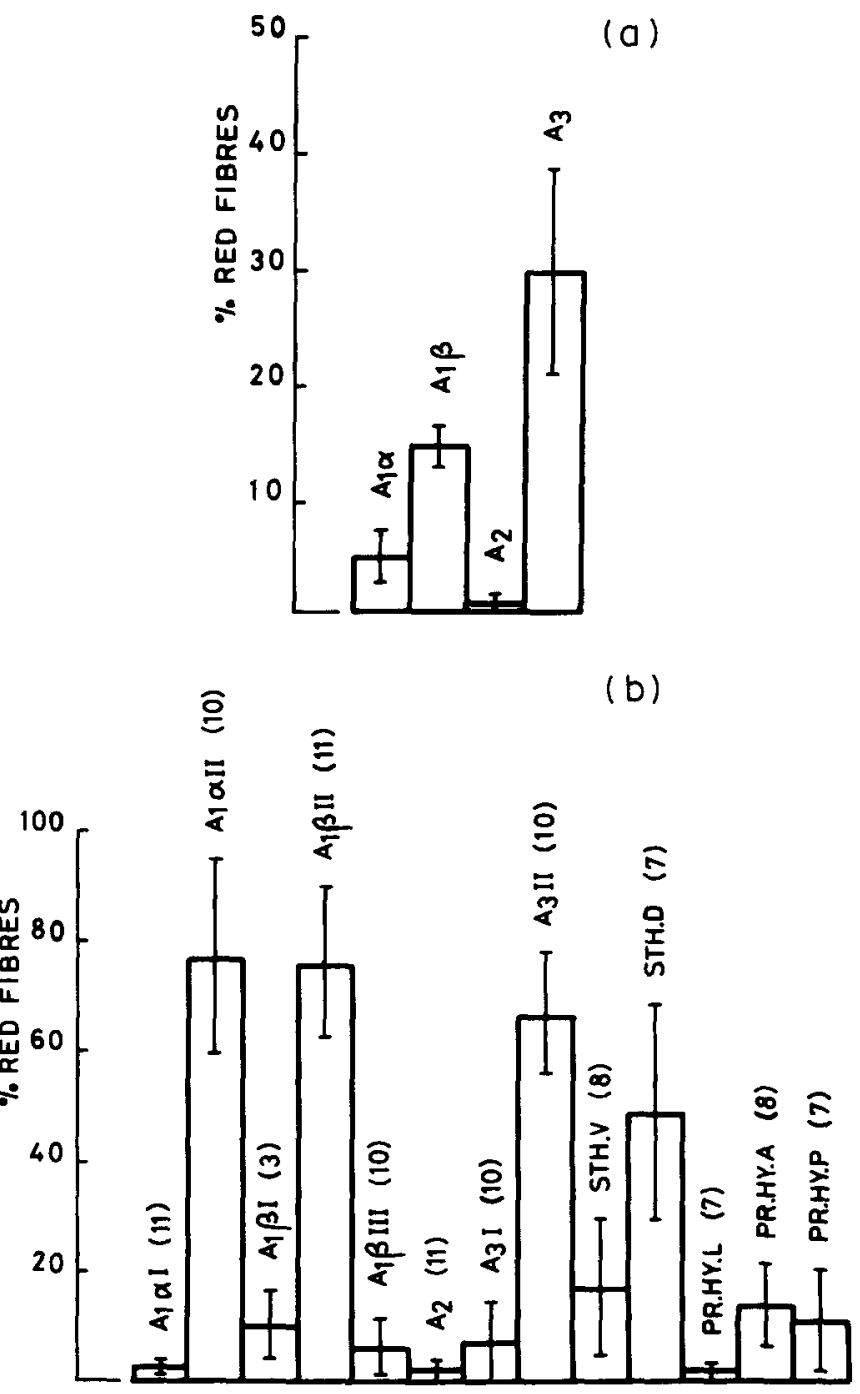

Fig. 4. Percentage of red fibres calculated from SDS polyacrylamide gel electrophoresis patterns of actomyosins. (A) The whole four adductor mandibulae (mean of 3 carps), (B) the different parts of adductor mandibulae, sternohyoideus and protractor hyoideus muscles. (Values in brackets represent the number of specimens analysed), (I) SEM. 
ments on living fish during different activities (Vandewalle et al., 1983). The various parts selected from the four jaw adductor muscles of 11 specimens (weighing 1.1-3.2 kg) are depicted in Fig. 1. The sternohyoideus muscle ( 2 parts: STH.V. and STH.D) and the protractor hyoideus muscle (3 parts: PR.HY.L, PR.HY.A and PR. HY. P) were included in this study, some of these muscles showing a peculiar sarcoplasmic proteinic composition (Hamoir et al., 1981).

Actomyosins of the various muscle parts were compared to white and red ones on one-dimensional polyacrylamide gels electrophoresis in SDS. Percentage of red fibres calculated from densitometer traces of gels are summarized in Fig. 4(B). They show obviously the existence in a single muscle of parts with a different fibre composition. For example, add.mand. $A_{1} \alpha$, which is assumed to be a "white" muscle according to its myosin type, appears to contain a part having as much as $80 \%$ of red fibres $\left(A_{1} \alpha I I\right)$. That part is proportionately very small with regard to the white part $A_{1} \propto I$. The distribution of the red myosin coincides with that of myoglobin.

\section{DISCUSSION}

As in higher vertebrates, myosin light chains of fast white and slow red carp muscles differ in their molecular weights. One-dimensional electrophoresis in the presence of SDS allows the estimation of the amount of the slow fibres present in heterogeneous muscles. Calculation of respective amount of white and red myosin light chains takes into account the stoichiometry of alkali white light chains and their molecular weights. In the case of the carp adductor mandibulae muscles, the percentage of red type fibres increases in the following ordering $A_{2} \rightarrow A_{1} \alpha \rightarrow A_{1} \beta \rightarrow A_{3}$. The results remain identical using either $\left(\mathrm{LC}_{1} \mathrm{~W}+\mathrm{LC}_{3} \mathrm{~W}\right)$ or $\mathrm{LC}_{3} \mathrm{~W}$ alone assuming that its percentage in carp trunk muscle is valid in the case of the other muscles examined. Distribution of myosin isoenzymes from white fibres appears thus constant, in the trunk and head muscles. Twodimensional electrophoresis does not permit a quantitative estimation but allows evaluation of change in composition between the various muscles. This method confirms the results of one-dimensional electrophoresis and appears particularly convenient to differentiate fish and rabbit myosins: carp and rabbit myosin light chains are all distinct in a same muscle type. They set up a good test of identification for any muscle and animal type.

Other biochemical studies also confirm our observations. The comparative work on carp head muscles has been extended to the sarcoplasmic proteins (Hamoir et al., 1981). The wide range of activities of these muscles is reflected in their sarcoplasmic composition: muscles involved in respiration (Ballintijn, 1969b) like $A_{3}$ is of the red type with a low total parvalbumin content, a large amount of parvalbumin $\mathrm{PA}_{1}$ and a lactate dehydrogenase (E.C. 1.1.1.27) pattern similar to that of cardiac muscle. On the other hand, the previous comparison of the contractile proteins of four parts of the adductor mandibulae muscles from the perch revealed a higher amount of slow type myosin and a lower parvalbumin content in sarcoplasm in the add.mand. $\mathbf{A}_{3}$ (Focant et al., 1981).

From the physiological point of view, electromyographic studies of Ballintijn (1969b) and Ballintijn et al. (1972) on carp and of Osse (1969) on perch, show that, during various movements of the mouth, activity occurs in the two groups of jaw adductor muscles: in the maxillary group, $A_{1} \beta$ contracts always longer than $A_{1} \alpha$ confirming the reddish characteristic of the first one; in the mandibulary group, activity occurs in the $A_{3}$ during the closing of the mouth with the occasional contribution of $A_{2}$ to increase the speed. Add.mand. $A_{3}$ muscle may act during movements of variable strength and duration (slow respiratory movements) while add.mand. $A_{2}$ is used during strong activity of short duration as feeding. This behaviour agrees with the noticeable red or slow myosin content of $A_{3}$ and the white or fast characteristic of add.mand. $A_{1} \alpha, A_{1} \beta$ and $A_{2}$.

Contrary to perch head muscles, carp homologous muscles were not subjected to histological and histochemical investigations.

However the heterogenous feature of most of adductor muscles revealed by electrophoresis was already visible during the dissection. The electrophoretic analysis of the actomyosin from the muscle parts isolated shows for example that a muscle classified as "white" $\left(A_{1} \alpha\right)$ contains a small area $(\mathrm{A}, \alpha \mathrm{II})$ composed of about $80 \%$ of red fibres. Our results confirm that add.mand. muscles are made of sets of white fibre bundles adjacent to red ones. The content in red fibres coincides with the myoglobin amount responsible for the red colour which is used for the dissection of the muscle parts.

Electromyographical results obtained at the same time on these muscle parts (Vandewalle et al., 1983) were strengthened in the light of our observations: $A_{1} \alpha$ II, $A_{1} \beta$ II and $A_{3}$ II red fibres bundles are mobilized in low amplitude movements as well as in slow respiration while the white (or pink) and these red muscles together work during coughing and strong respiration.

Our results exhibit a similar puzzle with the sternohyoïdeus and the protractor hyoideus muscles which agrees very well with the study of the corresponding sarcoplasmic proteins (Hamoir et al., 1981). Among these muscle parts, the laterally located part of protractor hyoideus (PR.HY.L) is particulariy interesting: the fibres appear devoid of myoglobin but contain red type $\mathbf{P A}_{1}$ parvalbumin and a lactate dehydrogenase isozymic distribution which looks more similar to that of red muscle. Our analysis of the actomyosin of that muscle shows that the myosin light chain pattern is similar to that of white muscle. The presence of a white muscle with a low parvalbumin content and aerobic metabolism does not fit with the earlier classification in three types of fibres. Those muscle samples were neglected in our electromyographic work. They should be also reexamined at the light of histological and histochemical methods.

Although they are limited, our observations show that head muscles do not act as homogeneous fibre assemblies but are constructed of different fibre bundles. Biochemical and electromyographical data gained from whole muscle analysis must be inter- 
preted very cautiously. On the other hand, myosin light chains confirm to be a very useful test for the differentiation in white or red muscle and agree well with the amount of myoglobin and the physiological activity of the muscle.

Acknowledgements-The authors are greatly indebted to Prof. G. Hamoir for his interest in this study. The financial support of the Belgian "Fonds de la Recherche Scientifique Médicale" is gratefully acknowledged (research contract No. 3.451.581)

\section{REFERENCES}

Akster H. A. (1981) Ultrastructure of muscle fibres in head and axial muscles of the perch (Perca fluviatilis L.) Cell Tissue Res. 219, 111-131.

Akster H. A. and Osse J. W. M. (1978) Muscle fibre types in head muscles of the perch Perca fluviatilis L., Teleostei. Neth. J. Zool. 28, 94-110.

Ballintijn C. M. (1969a) Functional anatomy and movement coordination of the respiratory pump of the carp ( $\mathrm{Cy}$. prinus carpio L.). J. exp. Biol. 50, 547-567.

Ballintijn C. M. (1969b) Muscle coordination of the respiratory pump of the carp (Cyprinus carpio L.). J. exp. Biol. 50, 569-591.

Ballintijn C. M., van den Burg A. and Egberink B. P. (1972) An electromyographic study of the adductor mandibulae complex of a free-swimming carp (Cyprinus carpio L.) during feeding. $J$. exp. Biol. 57, 261-283.

Focant B. and Huriaux F. (1976) Light chains of carp and pike skeletal muscle myosins. Isolation and characterization of the most anodic light chain on alkaline $\mathrm{pH}$ electrophoresis. FEBS Lett. 65, 16-19.

Focant B., Huriaux F. and Hogge J. M. (1974) Etude des chaînes légères de la myosine de muscle blanc de carpe. Archs int. Physiol. Biochim. 82, 985-987.

Focant B., Huriaux F. and Johnston I. A. (1976) Subunit composition of fish myofibrils: the light chains of myosin. Int. J. Biochem. 7, 129-133.

Focant B., Jacob M. F. and Huriaux F. (1981) Electrophoretic comparison of the proteins of some perch (Perca fluviatilis L.) head muscles. J. Muscle Res. Cell Motility 2, 295-305.
Focant B., Huriaux F. and Vandewalle P. (1982) Electrophoretic and electromyographic study of some head muscles of carp. J. Muscle Res. Cell Motility 3, 123.

Hamoir G., Focant B. and Disteche M. (1972) Proteinic criteria of differentiation of white, cardiac and various red muscles in carp. Comp. Biochem. Physiol. 41B, 665-674.

Hamoir G., Gerardin-Otthiers N., Grodent V. and Vandewalle P. (1981) Sarcoplasmic differentiation of head muscles of the carp, Cyrpinus carpio (Pisces, Cypriniformes). Molec. Physiol. 1, 45-58.

Huriaux F. and Focant B. (1974) Etude comparative, par électrophorèse en gel de polyacrylamide, des myofibrilles des muscles blanc, cardiaque et rouges de carpe. Archs int. Physiol. Biochim. 82, 991-992.

Huriaux F. and Focant B. (1977) Isolation and characterization of the three light chains from carp muscle myosin Archs int. Physiol. Biochim. 85, 917-929.

Huriaux F. and Focant B. (1978) Effect of some factors on the molecular weight determination of a light chain $\left(\mathrm{LC}_{3}\right)$ of carp (Cyprinus carpio L.) skeletal muscle myosin by SDS polyacrylamide gel electrophoresis. Comp. Biochem. Physiol. 61, 195-198.

Johnston I. A., Davison W. and Goldspink G. (1977) Energy metabolism of carp swimming muscles. J. comp. Physiol. 114, 203-216.

Laemmli U. K. (1970) Cleavage of structural proteins during the assembly of the head of Bacteriophage T4. Nature, Lond. 227, 680-685.

O'Farrell P. H. (1975) High resolution two-dimensional electrophoresis of proteins. J. biol. Chem. 250, 4007-4021

Osse J. W. M. (1969) Functional morphology of the head of the perch (Perca fluviatilis L.): an electromyographic study. Neth. J. Zool. 19, 289-392.

Syrovy I., Gaspar-Godfroid A. and Hamoir G. (1970) Comparative study of the myosins from red and white muscles of the carp. Archs int. Physiol. Biochim. 78, 919-934.

Vandewalle P. (1979) Etude cinématographique et électromyographique des mouvements respiratoires chez trois cyprins: Gobio gobio (L.), Barbus barbus (L.) et Leuciscus leuciscus (L.). Cybium 6, 3-28.

Vandewalle P., Monfils T., Huriaux F. and Focant B. (1983) Activités musculaires des faisceaux rouges et roses de l'adducteur de la mandibule chez la carpe (Cyprinus carpio L.) pendant la respiration et la toux. Ann. Soc. zool. Belg. 113, 133-140. 